\title{
Study of Wear, Hardness and Fractography of Millscale Reinforced Ceramic Matrix Composites
}

\author{
Stephen Durowaye ${ }^{1}$, Olatunde Sekunowo and Ganiyu Lawal \\ Department of Metallurgical and Materials Engineering, University of Lagos, Nigeria \\ ${ }^{1}$ Corresponding author: sdurowaye@unilag.edu.ng
}

Received: Dec 30, 2018

Revised: Feb 25, 2019

Accepted: Feb 27, 2019

\begin{abstract}
Ceramic matrix composites were developed by powder metallurgy and the blended matrix was reinforced with millscale particles from 3-18 wt.\% at particles size distribution of 106-250 $\mu \mathrm{m}$. Microstructural, hardness and wear characterisations were carried out on the composites using standardised methods. The results showed that the $106 \mu \mathrm{m}$ millscale particles reinforced composite exhibited desirable hardness value of 124 BHN, low wear rate of $1.99 \times 10^{-6} \mathrm{~g} / \mathrm{m}$ and appreciable high wear resistance indicating a potential for effective performance in service. The composites worn surfaces revealed abrasion, adhesion and grooves formation. These features derived from the composites microstructure formed the basis on which enhancement procedures could be developed.
\end{abstract}

Keywords: Ceramic matrix composite, powder metallurgy, hardness, wear, fractography

\section{Introduction}

Wear is a process of gradual materials removal from the surfaces of solids due to interaction with mating surfaces. Specifically, materials removal could be by physical separation due to micro fracture, chemical dissolution, or by melting at the contact interface and the detached materials become loose wear debris. There have been intensive studies on wear particles and some types of wear have been identified among which are adhesive, abrasive, thermal, oxidative, fatigue, and corrosive $[16,17]$. The dominant wear mode may change from one to another due to changes in surface material properties and dynamic surface responses caused by frictional heating and chemical film formation [17].

In order to obtain qualitative information on wear, visual inspection of the worn surfaces and wear debris is often used. The easiest method of visual inspection of surface damage is to photograph the surface. Furthermore, the worn surfaces can be examined with the aid of optical microscopes, scanning and transmission electron microscopes. The depth of debris removed from rubbing surfaces can be obtained by surface topographic measurements and the amount of materials worn away can be estimated. A post facto analysis of worn surfaces that describes the combination of wear mechanism with materials removal process usually defines the wear failure mode. The most common wear failure modes are ploughing, wedge formation, cutting, gouging, grinding, indenting, surface craters, pitting, spalling, delamination, scuffing and seizure [6]. Generally, it is difficult or challenging to predict and control the wear of rubbing elements due to many factors involved, e.g., environment (temperature, humidity, oxygen content), contact (normal load, sliding speed, type of 
motion), and materials properties such as hardness, surface roughness, contaminations, porosity, and interfacial bond of reinforcement [11].

Although it is a surface phenomenon, wear is a serious problem in many engineering applications such as bearing, moving parts, engine parts, etc. because a lot of machines lose their reliability and durability due to wear. It can also lead to structural failure directly or as part of a combination of effects. In either case, it can reduce fine tolerances and destroy a surface finish requiring early replacement of components. Hence, there is increasing need for economical, light weight, hard and wear resistant materials in many engineering applications which ceramic matrix composites (CMCs) have found applications. In view of these, the aim of this work is to develop particulate CMCs and also evaluate their hardness characteristics and dry sliding wear behaviour over a range of loads at a constant sliding speed.

\section{Materials and Methods}

\subsection{Materials}

The iron millscale was sourced from Universal Steel Nigeria Limited which is located in Ogba, Lagos. Silica sand was obtained from the beach of the Lagos Atlantic Ocean. Magnesia and bentonite powders were obtained from a local vendor within the chemicals supplier trade group registered in Nigeria but were manufactured in China and Wyoming, USA respectively.

\subsection{Production of the Composite Samples}

The iron millscale was milled in a steel ball mill (model A50 43, Mashine, France) and sieved to particles size distribution of 106-250 $\mu \mathrm{m}$ using standardised sieves (BSS). The matrix containing $212 \mu \mathrm{m}$ silica sand, $15 \mu \mathrm{m}$ bentonite, and $53 \mu \mathrm{m}$ magnesia was separately mixed with varied iron oxide granules $(106-250 \mu \mathrm{m})$. A uniform distribution of reinforcement particles in the matrix was achieved by mechanical mixing of the powders formulated for each blend. Distilled water in the proportion of $12 \mathrm{wt} . \%$ of the total mixture was added and the mixture was mixed again. Eighty grammes of each of the seven (7) material formulation was fed into fabricated metallic molds and green samples were obtained at $0.33 \mathrm{MPa}$ using a hydraulic press. Ease of samples discharge was facilitated by rubbing lubricant on the inner surfaces of the moulds.

Table 1: Materials formulation

\begin{tabular}{cccc}
\hline $\begin{array}{c}\text { Iron Millscale } \\
\text { (wt. \%) }\end{array}$ & $\begin{array}{c}\text { Silica } \\
\text { (wt. } \%)\end{array}$ & $\begin{array}{c}\text { Bentonite } \\
\text { (wt. } \%)\end{array}$ & $\begin{array}{c}\text { Magnesia } \\
\text { (wt. } \%)\end{array}$ \\
\hline $\mathbf{0}$ & 30 & 30 & 40 \\
$\mathbf{3}$ & 29.1 & 29.1 & 38.8 \\
$\mathbf{6}$ & 28.2 & 28.2 & 37.6 \\
$\mathbf{9}$ & 27.3 & 27.3 & 36.4 \\
$\mathbf{1 2}$ & 26.4 & 26.4 & 35.2 \\
$\mathbf{1 5}$ & 25.5 & 25.5 & 34 \\
$\mathbf{1 8}$ & 24.6 & 24.6 & 32.8 \\
\hline
\end{tabular}




\subsection{Drying and Sintering}

The samples were dried in open air for 3 days, followed by drying under a controlled humidity using an oven dryer at $110^{\circ} \mathrm{C}$ for 24 hours to remove any moisture left in the composites and to avoid cracking during sintering. In order to facilitate the bonding of powder particles, the compacted samples were gradually heated to temperatures below the melting point of the materials but high enough to develop significant solid state diffusion. Sintering was carried out at $600^{\circ} \mathrm{C}$, $800^{\circ} \mathrm{C}, 1000^{\circ} \mathrm{C}$, and $1200^{\circ} \mathrm{C}$ in a muffle furnace pre-set at heating rate of $10^{\circ} \mathrm{C} / \mathrm{min}$. The samples were soaked for 3 hours at each sintering temperature. After sintering, they were removed from the furnace and allowed to cool. The cooled samples were then characterised. Some of the produced ceramic composites are shown in Fig. 1.

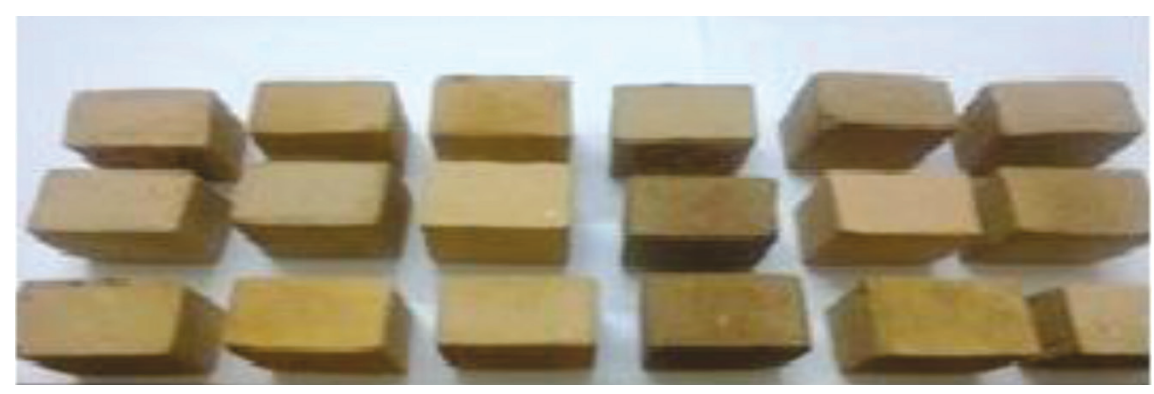

Fig. 1: Picture of the synthesized ceramic matrix composites

\subsection{Microstructural Characterisation}

The microstructure and the chemical compositions of the phases present in the test samples were examined using an ASPEX 3020 model variable pressure scanning electron microscope (SEM) equipped with Noran-Voyager energy dispersive X-ray spectroscope (EDS). The samples were mounted on a conductive carbon imprint left by the adhesive tape prepared by placing the samples on the circular holder and coated for five minutes to enable it conduct electricity. The samples were analysed at an accelerating voltage of $15 \mathrm{kV}$ for the energy dispersive $\mathrm{X}$-ray spectroscopy.

\subsection{Hardness Characterisation}

The hardness test was done on samples having dimension $25 \mathrm{~mm} \times 25 \mathrm{~mm} \times 10 \mathrm{~mm}$ in accordance with ASTM E10 standard using a Brinell hardness measuring machine of $20 \mathrm{kN}$ capacity. Each sample was mounted on the machine and a load of $5 \mathrm{kN}$ was applied on it for about 10 seconds. The diameter of indentation left in the sample was measured with a low powered microscope and the hardness number was obtained using equation (1).

$$
\text { Hardness }(\mathrm{HBN})=\frac{2 \mathrm{P}}{\pi \mathrm{D}\left[\mathrm{D}-\sqrt{\mathrm{D}^{2}-\mathrm{d}^{2}}\right]} \text { Hardness }(\mathrm{HBN})=\frac{2 \mathrm{P}}{\pi \mathrm{D}\left[\mathrm{D}-\sqrt{\mathrm{D}^{2}-\mathrm{d}^{2}}\right]}
$$

where $\mathrm{P}$ is load (kgf), D is diameter of indenter $(\mathrm{mm}), \mathrm{d}$ is the diameter of indentation $(\mathrm{mm})$, $\pi=3.142$

\subsection{Wear and Fractography}

Dry sliding abrasive wear test was conducted on the samples using a pin-on-disc wear tester according to ASTM G99 standard at room temperature. Wear test was conducted with loads 
ranging from 8 to $24 \mathrm{~N}$ and sliding speed of $4.19 \mathrm{~m} / \mathrm{s}$. The specific wear rate was determined using Equations (2) and (3) $[4,10]$ and the fractography of the worn surfaces of the samples was examined using a scanning electron microscope (SEM).

$$
\begin{array}{ll}
\mathrm{R}=\frac{\Delta \mathrm{w}}{\mathrm{L}}=\frac{\Delta \mathrm{w}}{\mathrm{L}} & \\
\mathrm{L}=2 \pi \mathrm{NDt} & \mathrm{L}=2 \pi \mathrm{NDt}
\end{array}
$$

where $\mathrm{R}$ is the wear rate, $\pi=3.142$.

$\Delta \mathrm{W}=$ difference between the initial and final weights of the samples

$\mathrm{L}=$ sliding distance in $\mathrm{m}$.

$\mathrm{D}=$ diameter of the $\mathrm{P} 36$-grit sandpaper (abrasive) which is $16 \mathrm{~cm}$

$\mathrm{N}=$ revolution per minute of the pin-on disc which is $250 \mathrm{rpm}$

$\mathrm{t}=$ time taken to expose each of the samples to wear simulation which is 5 mins

\section{Results and Discussion}

\subsection{Microstructure}

The SEM micrographs in Figs. 2 - 4 show that the samples are made up of different additives which confirm that they are heterogeneous with differences in the geometry of the particles which are globular and needle-like. The EDS spectrographs show a good combination of the elemental distribution which also reflects on the heterogeneous nature of the composites. The EDS spectrographs of the samples show the presence of $\mathrm{O}, \mathrm{Si}, \mathrm{Al}, \mathrm{Mg}, \mathrm{Fe}$, and $\mathrm{Ca}$ but the unreinforced does not contain Fe (Fig. 2). The white spots in the micrographs are particles of the magnesia $(\mathrm{MgO})$ while the dark spots are $\mathrm{FeO}$ particles from the iron millscale. The ash coloured needle-like region is mullite $\left(3 \mathrm{Al}_{2} \mathrm{O}_{3} \cdot 2 \mathrm{SiO}_{2}\right)$ while the gray mixed with whitish spots are the spinel as shown in Figs. 2 - 4. From the micrograph of the reinforced samples in Figs. 3 and 4, FeO particles are well distributed in the matrix without any form of segregation.
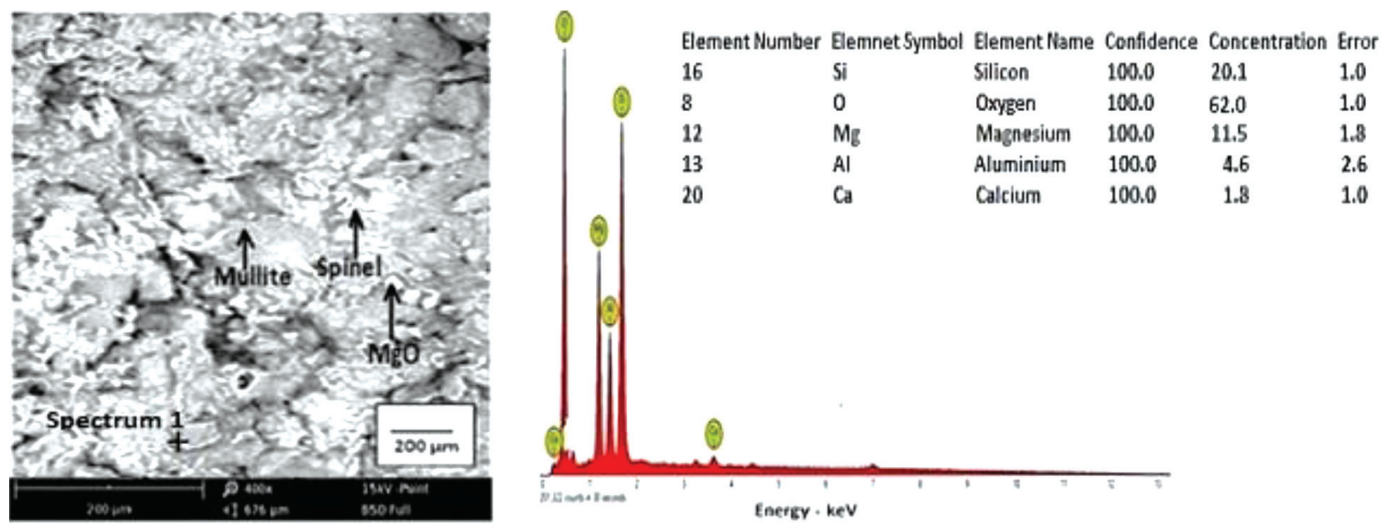

Fig. 2: SEM micrograph and EDS of the unreinforced ceramic matrix composite

\subsection{Hardness}

From the results shown in Fig. 5, the hardness values of the samples were high. This is attributable to the presence of silica $\left(\mathrm{SiO}_{2}\right)$, magnesia $(\mathrm{MgO})$, alumina $\left(\mathrm{Al}_{2} \mathrm{O}_{3}\right), \mathrm{FeO}, \mathrm{Fe}_{2} \mathrm{O}_{3}$, and $\mathrm{CaO}$ which are hard materials $[7,2]$. 

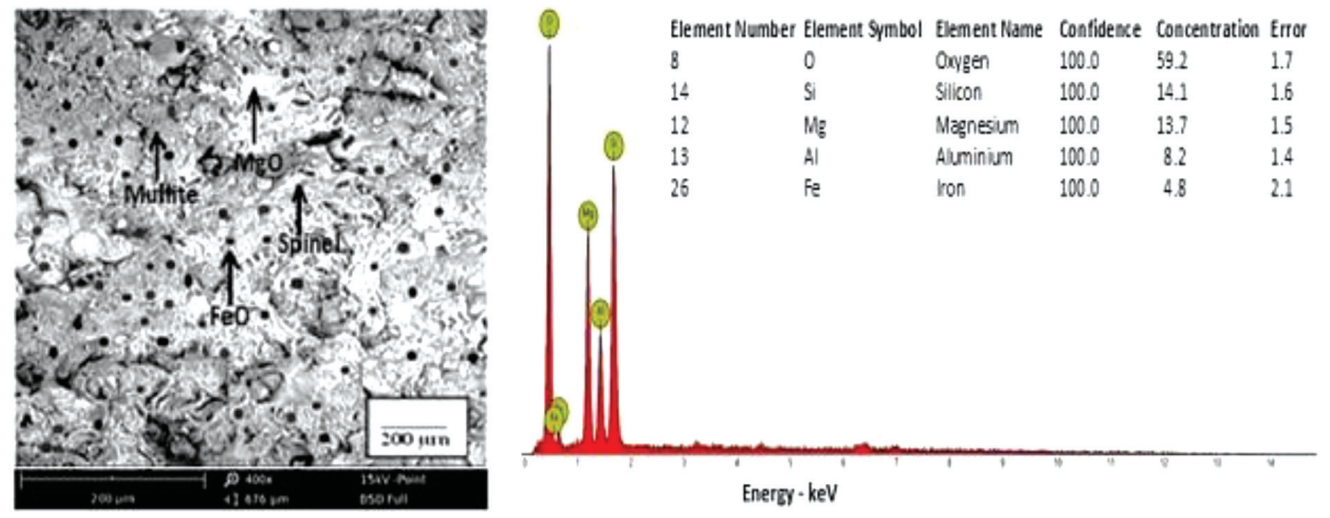

Fig. 3: SEM micrograph and EDS of the $15 \mathrm{wt}$ \% $106 \mu \mathrm{m}$ iron millscale reinforced ceramic composite
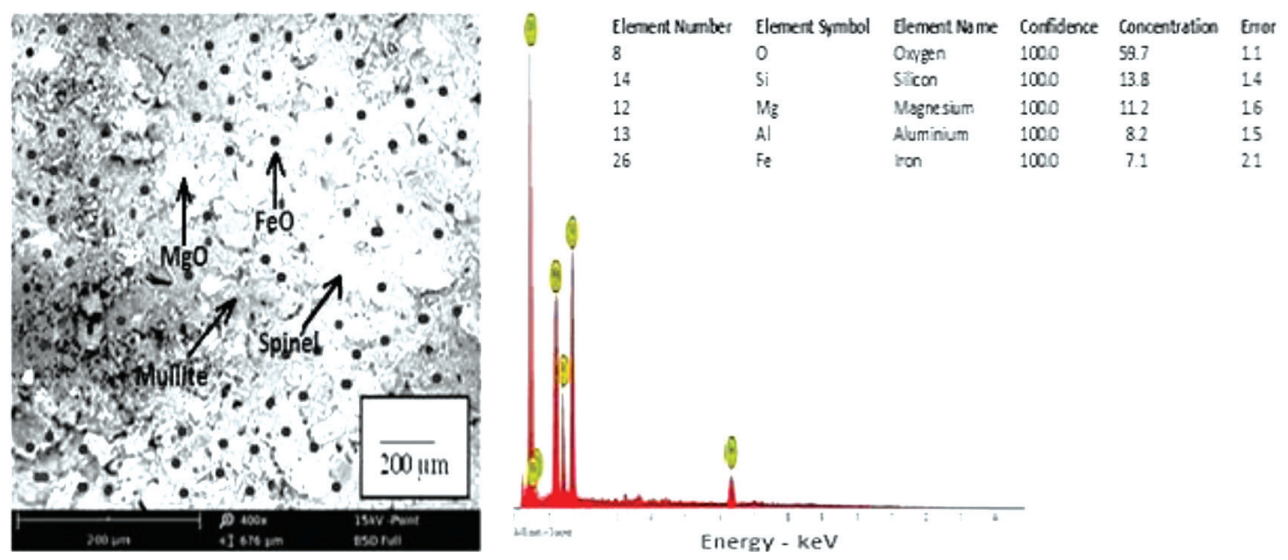

Fig. 4: SEM micrograph and EDS of the $15 \mathrm{wt} \% 180 \mu \mathrm{m}$ iron millscale reinforced ceramic Composite

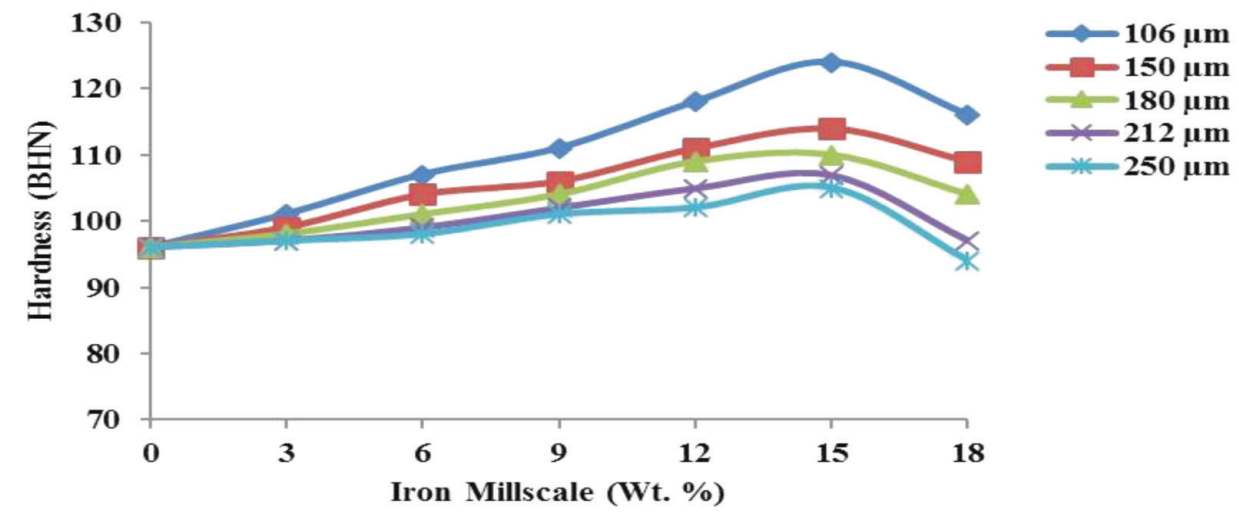

Fig. 5: Hardness of the composites at varied iron millscale addition

The hardness of the composites increased with decreasing size of iron millscale particles and the 
$106 \mu \mathrm{m}$ millscale reinforced sample exhibited the highest hardness value of $124 \mathrm{BHN}$ at $15 \mathrm{wt} . \%$ reinforcement. This represents $29 \%$ increase over the unreinforced which is significant. The high hardness values of the $106 \mu \mathrm{m}$ millscale reinforced sample was due to reduced size of millscale particles. Small size particles enhanced densification which in turn enhanced the mechanical properties better than coarse particles of the same concentration [13]. The results attested to the fact that ceramic materials exhibit very high hardness [3]. A decrease in the hardness value of the composites was observed when reinforcement was beyond $15 \mathrm{wt}$. \%. This may be due to the effect of increasing $\mathrm{FeO}$ content that is rich in iron which might have increased the plasticity of the composite. Weak interfacial bonding of the reinforcement and matrix particles could also be responsible for the decrease in the hardness beyond $15 \mathrm{wt}$ \% reinforcement.

\subsection{Wear Rate}

As presented in Figs. 6 - 10, the wear rate of the composites increased with increasing applied load. This was due to plastic deformation of the composites in the friction surface as a result of increase in the shear force between asperities and the ploughing force of asperities. Similar observation was also reported by Djafri et al. [5]. The $106 \mu \mathrm{m}$ millscale reinforced composite exhibited the lowest wear rate of $1.99 \times 10^{-6} \mathrm{~g} / \mathrm{m}$ at maximum load of $24 \mathrm{~N}$. In the reinforced composites, the highly reinforced samples (15 and $18 \mathrm{wt} . \%$ ) exhibited the lowest wear rate. This indicated the effect of concentration of millscale reinforcement in reducing wear. This observation was similar to the one reported by Aigbodion and Akadike [1].
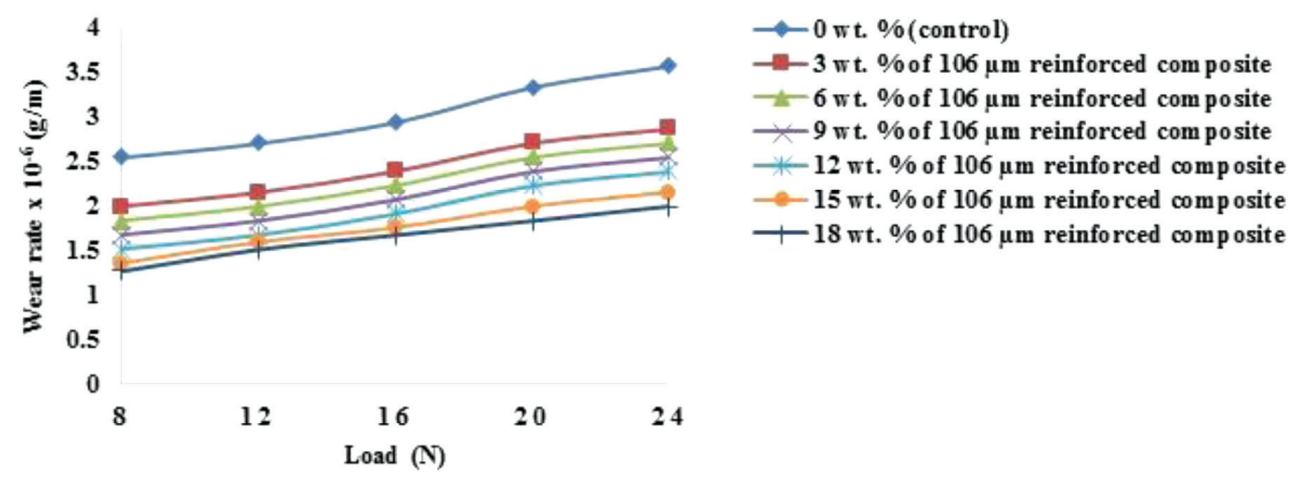

Fig. 6: Wear rate of the $106 \mu \mathrm{m}$ iron millscale particles reinforced ceramic composites

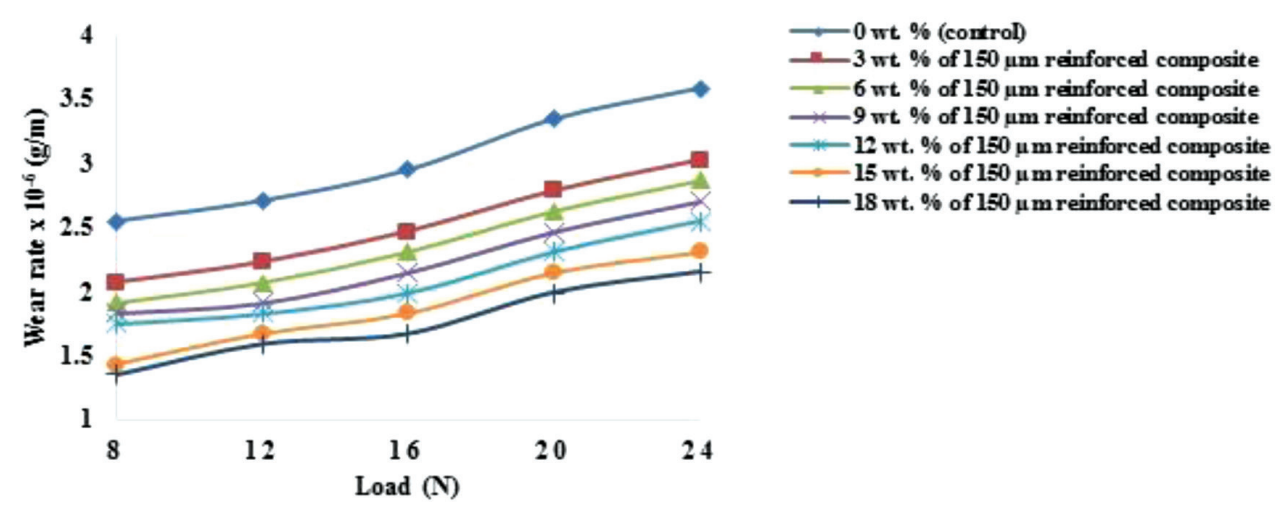

Fig. 7: Wear rate of the $150 \mu \mathrm{m}$ iron millscale particles reinforced ceramic composites 

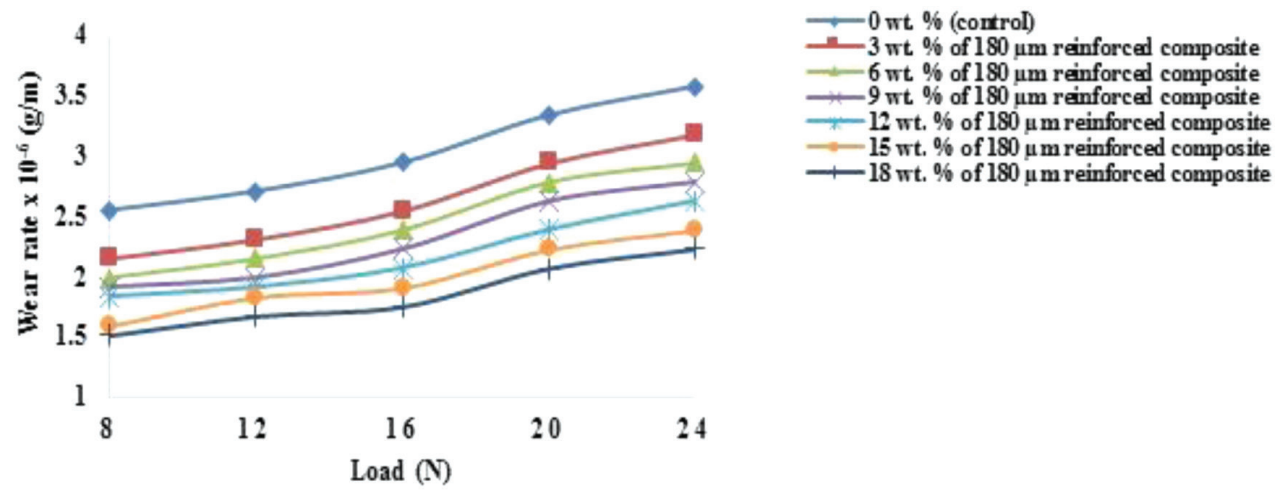

Fig. 8: Wear rate of the $180 \mu \mathrm{m}$ iron millscale particles reinforced ceramic composites
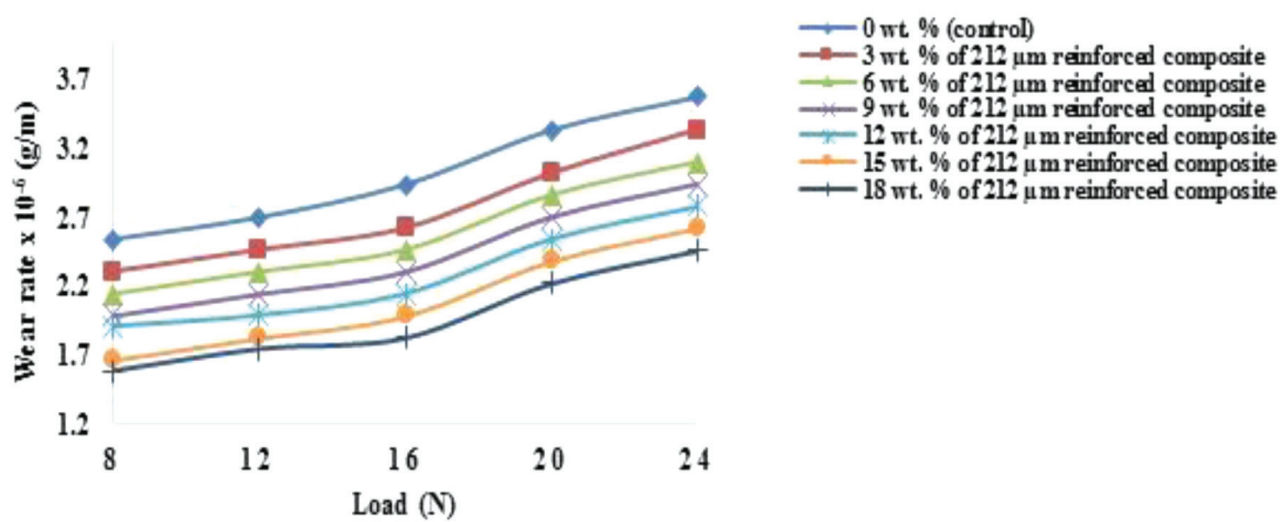

Fig. 9: Wear rate of the $212 \mu \mathrm{m}$ iron millscale particles reinforced ceramic composites
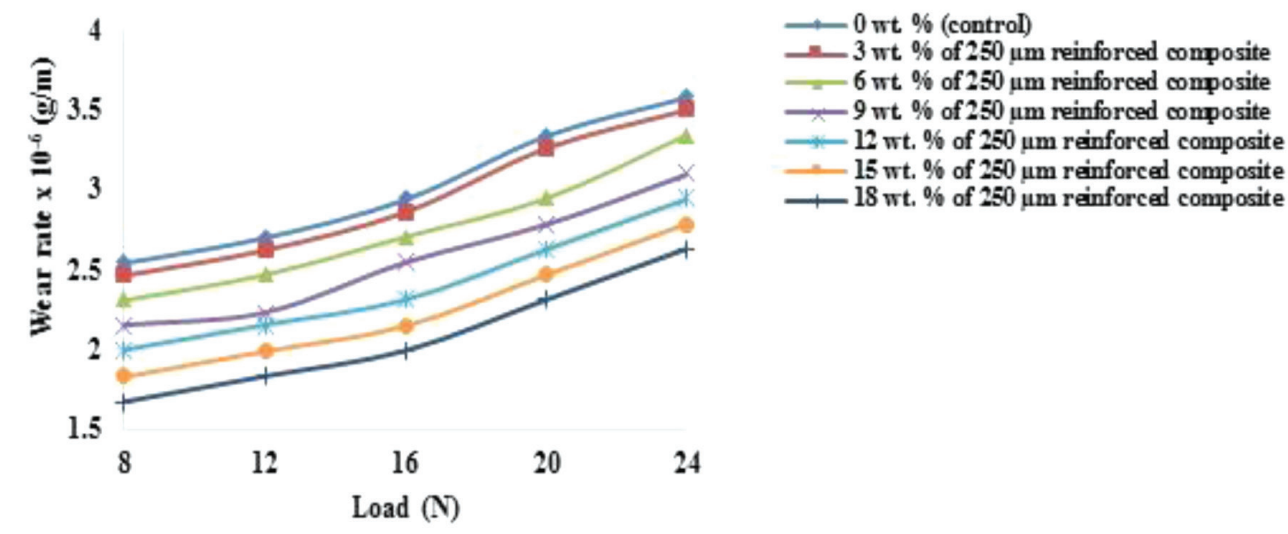

Fig. 10: Wear rate of the $250 \mu \mathrm{m}$ iron millscale particles reinforced ceramic composites 


\subsection{Fractography of Composites Worn Surfaces}

The SEM micrographs in Figs. 11 show the microstructure of the worn surfaces of the ceramic composites after wear tests at a speed of $4.19 \mathrm{~m} / \mathrm{s}$ and maximum applied load of $24 \mathrm{~N}$. Grooves were observed on the surfaces of the worn samples due to abrasion. The surfaces of the worn samples showed a typical abrasive wear mode in which abrasive particles (debris), scratches, shallow, and deep grooves were formed along the wear direction (parallel to disc rotation).

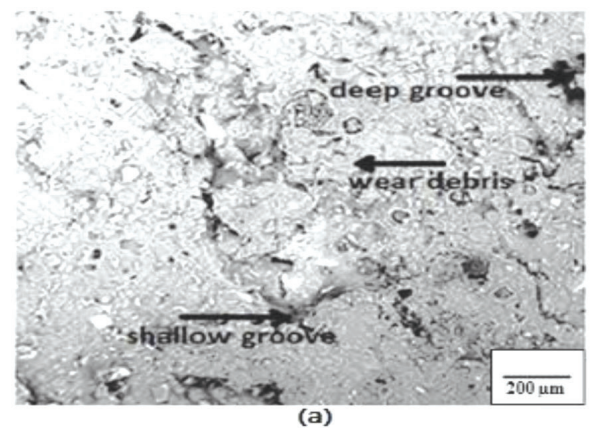

(a)

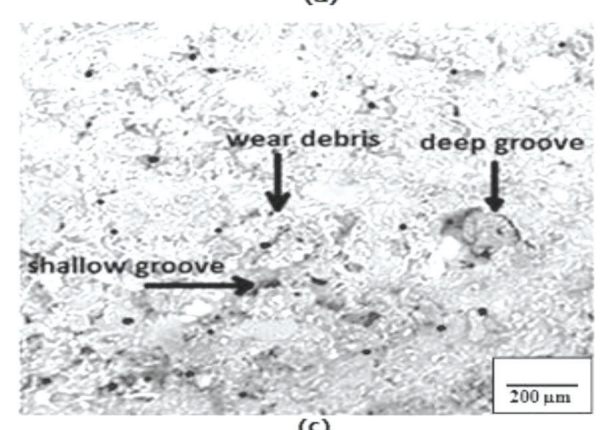

(c)

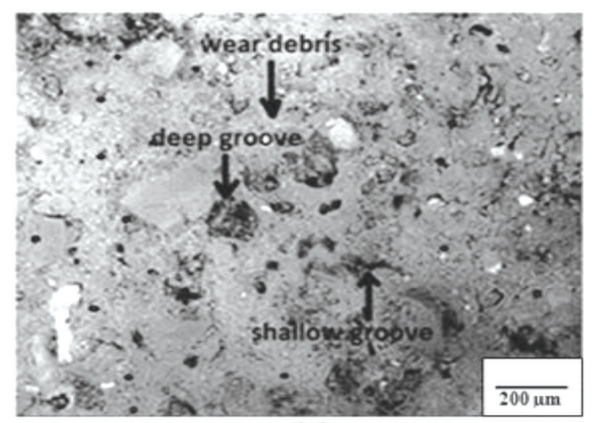

(e)

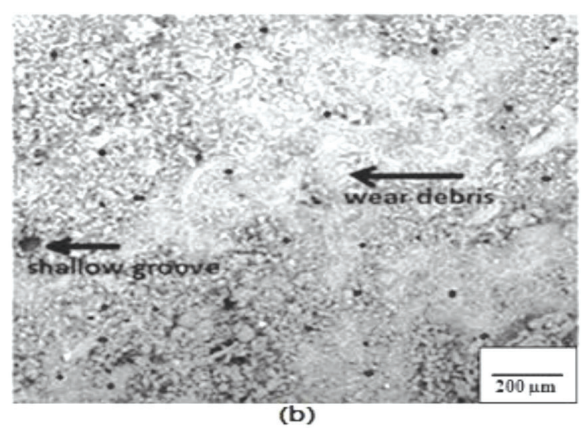

(b)

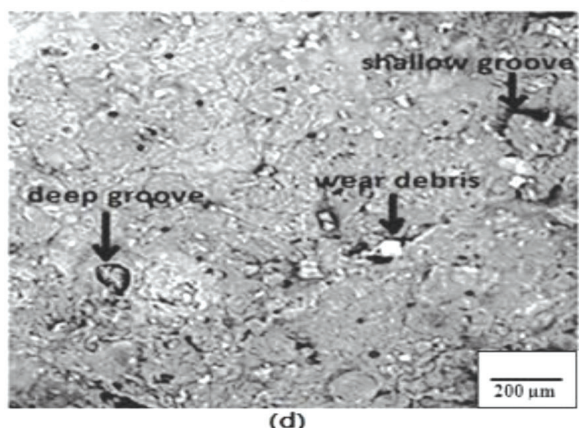

(d)

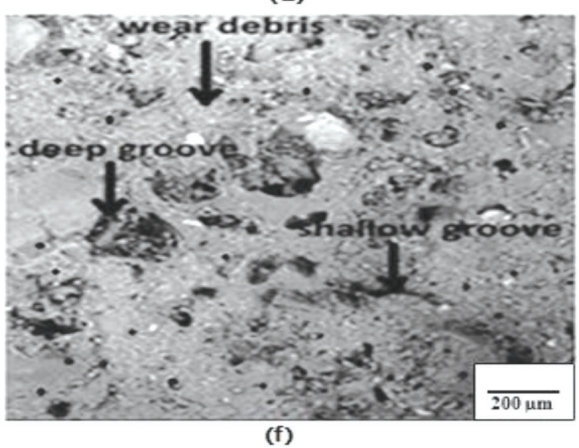

Figs. 11: Micrograph of worn surface of: (a) unreinforced composite, (b) $15 \mathrm{wt} . \% 106 \mu \mathrm{m}$ iron millscale particles reinforced composite, (c) $15 \mathrm{wt} . \% 150 \mu \mathrm{m}$ iron millscale particles reinforced composite, (d) 15 wt. $\% 180 \mu \mathrm{m}$ iron millscale particles reinforced composite, (e) $15 \mathrm{wt} . \% 212 \mu \mathrm{m}$ iron millscale particles reinforced Composite, and (f) 15 wt. $\% 250 \mu \mathrm{m}$ iron millscale particles reinforced composite

The wear grooves showed the evidence of severe plastic flow in the form of grooves parallel to the sliding direction. A similar observation was reported in [5]. It was also observed that the worn surface of the unreinforced composite (Fig. 11a) exhibited more groove defects than the reinforced (Figs. $11 \mathrm{~b}-11 \mathrm{f})$. The highly reinforced (15 and $18 \mathrm{wt}$. \%) composites manifested less scratches 
and grooves than the lowly reinforced composites. All these were supported by the fact that abrasive wear in contacting surfaces resulted in scratching, furrows, work hardening, or grooves $[8,9]$. The worn surfaces appeared to be rough on the microscopic scale. During the wear process, wear debris were generated and they were mainly fine powders that were either released into the environment or trapped between the contact areas. Occasionally, some of the wear debris may also be trapped in any available porous or void area of the samples. The wear debris accumulated and piled up against the contact areas. This phenomenon resulted in the contact areas increasing in size to form a friction layer and patches due to the compaction of wear debris trapped between the sliding surfaces. The debris in the micrographs enhanced the rate of wear of the samples. Similar observations were also reported by Sloan [14] and Ruzaidi et al. [12].

The micrographs of the worn samples revealed that abrasion, adhesion, and groove formation were the wear types that were in operation during the wear simulation. Abrasion is always characterised by the presence of shallow grooves of ploughed marks on the friction layers. This wear mechanism was observed in all the micrographs and a similar observation was reported by Talib et al. [15]. This phenomenon could be due to the hard particles of the ceramic materials which existed during the wear process that ploughed into the worn surfaces. Adhesion also occurred as the contact areas grew to form patches due to the compaction of wear debris trapped between the sliding surfaces. The smaller-the-better characteristics should be taken for obtaining optimal tribological behaviour. Wear of friction materials should be minimized as much as possible. A higher wear rate means shorter friction material life and thus, the incurring of more material and maintenance costs and vice versa for a lower wear rate.

\section{Conclusion}

The development and characterisation of millscale particles reinforced ceramic matrix composites using different weight percentages of reinforcement have been undertaken. Among the composites, the $106 \mu \mathrm{m}$ millscale particles reinforced composite exhibited desirable hardness value of 124 BHN and low wear rate of $1.99 \times 10^{-6} \mathrm{~g} / \mathrm{m}$ and appreciable high wear resistance indicating a potential for effective performance in service. The uniform distribution of the hard iron millscale particles in the matrix coupled with the strong interfacial bonding between the reinforcement and the matrix were responsible for the enhancement of these properties of the composites. Abrasion, adhesion, and groove formation were the wear types that were observed to be in operation during wear simulation. The severity of wear of the unreinforced was more than the reinforced samples indicating the effectiveness of reinforcement in enhancing wear resistance.

\section{References}

[1] Aigbodion VS and Akadike U (2010), Development of asbestos - free brake pad using bagasse, Tribology in Industry, 32(1): 45-50.

[2] Aku SY, Yawas DS, Madakson PB and Amaren SG (2012), Characterisation of periwinkle shell as asbestos-free brake pad materials, Pacific Journal of Science and Technology, 13(2): 57-63.

[3] Callister WD and Balasubramaniam R (2011), Materials Science and Engineering, $7^{\text {th }}$ Edition, Wiley India Pvt. Ltd., 4435-36/7, New Delhi-110002, India.

[4] Dan-Asabe B, Madakson PB and Manji J (2012), Material selection and production of a coldworked composite brake pad, World Journal of Engineering and Pure and Applied Science, 2(3): 92-97. 
[5] Djafri M, Bouchetara M, Busch C and Weber S (2014), Experimental study of the tribological behaviour of materials of brake, MECHANIKA, 20(4): 420-425.

[6] Gee MG, Hutchings IM and Santner E (2006), Friction and Wear, Handbook of Materials Measurement Methods, Springer, Chapter 13, 685-710. ISBN: 9783540207856.

[7] Hassan SB and Aigbodion VS (2010), Microstructure and interfacial reaction of Al-Cu-Mg/ bagasse ash particulate composite, Journal of Alloy \& Compounds, 491: 571-574.

[8] Holmberg K and Matthews A (2009), Coatings tribology, properties, mechanisms, techniques and applications in surface engineering, Tribology and Interface Engineering, 56(2): 560.

[9] Kumar A and Singh S (2011), Wear property of metal matrix composite. B. Tech. Thesis, National Institute of Technology, Rourkela, Odisha 769008, India.

[10] Olabisi AI, Ademoh NA and Okechukwu OM (2016), Development and assessment of composite brake pad using pulverized cocoa beans shells filler, International Journal of Materials Science and Applications, 5(2): 66-78.

[11] Riina R, Maksim A, Renno V and Simo-Pekka H (2014), Comparison of the wear and frictional properties of $\mathrm{Cu}$ matrix composites prepared by pulsed electric current sintering, Proceedings of the Estonian Academy of Sciences, 63(1): 62-74.

[12] Ruzaidi CM, Kamarudin H, Shamsul JB, Mustafa AM and Liyana J (2013), Mechanical properties and morphology of palm slag, calcium carbonate and dolomite filler in brake pad composites, Applied Mechanics and Materials, Trans Tech Publications, 313-314: 174-178.

[13] Sbaizero O and Pezzotti G (2000), Influence of the metal particle size on toughness of $\mathrm{Al}_{2} \mathrm{O}_{3}-\mathrm{Mo}$ composite, Elsevier, Acta Materialia-ACTA MATER, 48: 985-992.

[14] Sloan MR (2008), Eco-efficient friction materials, PhD Thesis, University of Exeter, United Kingdom.

[15] Talib RJ, Azimah MAB, Yuslina J, Arif SM and Ramlan K (2008), Analysis on the hardness characteristics of semi-metallic friction materials, Journal of Solid State Science \& Technology, 16(1): 124-129.

[16] Zmitrowicz A (2005), Wear debris: A review of properties and constitutive models, Journal of Theoretical and Applied Mechanics, 43(1): 3-13.

[17] Zmitrowicz A (2006), Wear patterns and laws of wear - a review, Journal of Theoretical and Applied Mechanics, 44(2): 219-253. 